\title{
COLOMBO PLAN
}

History. Founded in 1950 to promote the development of newly independent Asian member countries, the Colombo Plan has grown from a group of seven Commonwealth nations into an organization of 24 countries. Originally the Plan was conceived for a period of six years. This was renewed from time to time until the Consultative Committee gave the Plan an indefinite life span in 1980.

Members. (Permanent Member Countries) Afghanistan, Australia, Bangladesh, Bhutan, Cambodia, Fiji Islands, India, Indonesia, Islamic Republic of Iran, Japan, South Korea, Lao People's Democratic Republic, Malaysia, Maldives, Myanmar, Nepal, New Zealand, Pakistan, Papua New Guinea, Philippines, Singapore, Sri Lanka, Thailand, USA and Vietnam. (Provisional member country) Mongolia.

Aims. The aims of the Colombo Plan are: (1) to provide a forum for discussion, at local level, of development needs; (2) to facilitate development assistance by encouraging members to participate as donors and recipients of technical cooperation; and (3) to execute programmes to advance development within member countries. The Plan currently has the following programmes:

Programme for Public Administration (PPA). Initiated in 1995 to provide developing member country officials training in all sectors of public administration in the context of market-oriented economies, drawing on the experience of more developed economies in the region. The PPA conducts joint training programmes with member countries and sponsors participants on training courses conducted by the Asian Productivity Organization (APO) and the South East Asian Fisheries Development Centre (SEAFDEC). 1999 also saw the introduction of training programmes conducted in collaboration with the Asian Development Bank Institute (ADBI) in Tokyo.

South-South Technical Co-operation Data Bank Programme (SSTC/DB). Published a report in Dec. 1997 entitled South-South Technical Co-operation in Selected Member Countries covering technical co-operation activities of India, Indonesia, Malaysia, Pakistan, Philippines, Singapore and Thailand.

Drug Advisory Programme (DAP). Initiated in 1972, it works with governments, international bodies and NGOs in the region to deliver more effective anti-narcotics programmes. It works both in supply (controlling availability of drugs) and demand (helping counter the culture and providing assistance to addicts).

Programme for Private Sector Development (PPSD). In 1998 the PPSD conducted training programmes co-sponsored by the Asian Development Bank (ADB), the Malaysian Technical Co-operation Programme (MTCP) and the Pakistan Industrial Technical Assistance Centre (PITAC).

Colombo Plan Staff College for Technician Education (CPSC). Established in 1973, it trains management and technical staff from member countries. It is separately financed by most member countries and functions under the guidance of its own Governing Board, consisting of the heads of member countries' permanent diplomatic missions in the Philippines.

Structure. The Consultative Committee is the principal policy-making body of the Colombo Plan. Consisting of all member countries, it meets every two years to review the economic and social progress of members, exchange views on technical co-operation programmes and generally review the activities of the Plan. The Colombo Plan Council represents each member government and meets several times a year to identify development issues, recommend measures to be taken and ensure implementation.

Headquarters: 12 Melbourne Avenue, PO Box 596, Colombo 4, Sri Lanka.

e-mail: cplan@slt.lk

Secretary-General: Dr U Sarat Chandran (India).

Publications. Consultative Committee Meeting-Proceedings and Conclusions (biennial); Report of the Colombo Plan Council (annual); The Colombo Plan Brochure (annual); The Colombo Plan Focus (quarterly newsletter); South-South Technical Co-operation in Selected Member Countries. 